\title{
MANGANESE SPECIATION IN SELECTED AGRICULTURAL SOILS OF PENINSULAR MALAYSIA
}

\author{
Habibah, J., J. Khairiah, B.S. Ismail and M.D. Kadderi \\ School of Environmental and Natural Resource Sciences, Faculty of Science and Technology, \\ Universiti Kebangsaan Malaysia,43600 UKM Bangi, Selangor, Malaysia
}

Received 2013-11-19; Revised 2014-03-04; Accepted 2014-04-07

\begin{abstract}
Manganese speciation in selected agricultural soils of Peninsular Malaysia is discussed in this study. Manganese concentration in the Easily Leacheable and Ion Exchangeable (ELFE), Acid Reducible (AR), Organic Oxidizable (OO) and Resistant (RR) fractions of soils developed on weathered rocks, soils of mixed nature, alluvium and peat deposits are described. The total manganese concentration in soils developed on weathered rocks was found to be higher than that in soils of mixed nature, alluvium and peat deposits because of the occurrence of resistant manganese oxide at the topsoils. Manganese speciation in paddy soils is influenced by the redox condition resulting from the alternate flooding and drying of the soils. Under reducing conditions, this metal tends to get dissolved and be available for plant uptake. Upon oxidation, manganese is precipitated into the acid reducible fraction as poorly crystalline manganese oxide and hydroxide and/or the resistant Fe-Mn mottles. In non-paddy cultivated alluvial soils, manganese speciation varies widely and is less understood. For the non-paddy cultivated peat soils, manganese is mainly associated with organic material, as indicated by the high manganese concentration in the OO fraction.
\end{abstract}

Keywords: Mangenese Speciation, Agricultural Soils, Peninsular Malaysia

\section{INTRODUCTION}

Manganese is a metal commonly found in soils and is likely to occur as oxides and hydroxides in the form of coatings on other particles and as nodules of different diameters. The $\mathrm{Mn}$ oxides are mostly amorphous, but crystalline varieties have also been identified in soils (Kabata-Pendias and Pendias, 1984). Most of the Mn oxides have strong specific adsorption to cations, leading to high accumulation of other heavy metals. Such metals can be adsorbed onto the surface of minerals like clay, as well as Fe and/or Mn oxy-hydroxides (Quemerais et al., 1998). A study on serpentine soils of Ranau, Sabah indicated that over half of the soil $\mathrm{Co}$ is associated with Mn-oxide (Tashakor et al., 2011). In Australia, zones rich in Mn oxy-hydroxides occur as coatings on fissure surfaces, contained large concentrations of $\mathrm{Ce}$ and $\mathrm{U}$ (Koppi et al., 1996). Iron and manganese cycling has been observed to have strong correlation with redox conditions, seasonal fluctuation of boundary conditions and quantity and reactivity of organic matter (Marchand et al., 2006). Mn oxides also play an important role in the oxidation of $\mathrm{Cr}$ (III) to $\mathrm{Cr}(\mathrm{IV})$ in soils and the amounts of $\mathrm{Cr}(\mathrm{VI})$ produced through oxidation of $\mathrm{Cr}(\mathrm{III})$ by Mn oxides are related to the types of Mn oxides in the nodules, for example birnessite, lithiophorite, todorokite, lithiophorite and lithiophorite (Tan et al., 2005). Mn oxides incorporate metal ions in their mineral structure and/or act as high-surface-area substrates favouring heavy metal adsorption (Decree et al., 2010). The adsorption and desorption of heavy metals have been demonstrated to be associated with soil properties, including $\mathrm{pH}$, organic matter content, Cation Exchange Capacity (CEC), oxidation-reduction status (Eh) and the contents of clay minerals, calcium carbonate, as well as $\mathrm{Fe}$ and Mn oxides (Zeng et al., 2011).

Corresponding Author: Habibah, J., School of Environmental and Natural Resource Sciences, Faculty of Science and Technology, Universiti Kebangsaan Malaysia, 43600 UKM Bangi, Selangor, Malaysia 
Manganese compounds are important in soils because this metal is essential in plant nutrition and controls the behaviour of several other micronutrients (Kabata-Pendias and Pendias, 1984). The reduction and dissolution of $\mathrm{Mn}$ oxides increase the $\mathrm{Mn}$ mobility and bioavailability to organisms (Kämpf et al., 2000). As a micronutrient, mangenese is required in microquantities but deficiency of this metal can cause serious crop production and animal health problems. Some crops like beans, oat, potato, sorghum, soya bean and wheat are highly sensitive to micronutrient deficiencies whereas barley, clover, corn, grass, sugar beet and turnip show medium sensitivity (Gupta et al., 2008). Manganese deficiency generally occurs in soils with high pH (Clark, 1993). Response to manganese availability is most likely to occur in soils with high organic matter content, high-pH as well as in calcareous and sandy soils (Wiese, 1993). Excess manganese, for example in soils with high levels of water soluble or salt extractable Mn (Moraghan, 1979) may cause toxicity in plants. Manganese toxicity has been reported in crops grown on strongly acidic soils (Clark, 1993).

Heavy metal speciation has been successfully used as an indicator for heavy metal association in soil fractions (Iskandar and Kirkham, 2001), including the resistant and bioavailability forms, the acid reducible material and metal association with organic matter. For example, the sewage sludge amended soil contains high amounts of bioavailable $\mathrm{Zn}, \mathrm{Pb}, \mathrm{Fe}, \mathrm{Ce}$ and $\mathrm{Cu}$ (Rajoo et al., 2013). The understanding of heavy metal speciation could lead to the understanding of heavy metal behaviour and mobility in soils. Naturally, the bioavailable heavy metal will become a growing concern should its concentration exceed the threshold limit. In Peninsular Malaysia, heavy metal speciation studies have been carried out in selected agricultural soils (Habibah et al., 2011; Khairiah et al., 2006; Khairiah et al., 2009a; 2009b; 2009c; 2012). However, a comprehensive understanding of manganese speciation in agricultural soils of different origins has never been compared. In the present study, manganese speciation in selected agricultural soils developed on weathered rocks, soils of mixed nature at hill slopes and on alluvial and peat deposits are compared.

\section{MATERIALS AND METHODS}

The speciation method introduced by Badri and Aston (1983) was applied to understand Mn speciation in agricultural soils. This method was used to quantify heavy metal concentrations in four geochemical phases, namely the Easily Leacheable and Ion Exchangeable (ELFE), Acid Reducible (AR), Organic Oxidizable (OO) and Resistant (RR) fractions. Metals extracted in the first fraction will be those that exist loosely bonded or adsorbed on exchangeable surfaces of clay minerals and organic matter. Metals combined with hydrous and amorphous $\mathrm{Fe}$ and $\mathrm{Mn}$ oxides, carbonates, sulphides and others (reducible phase) will be extracted in the second fraction. In the oxidizable organic fraction metals bonded strongly to various kinds of organic compounds will be extracted. Metals in the resistant fraction will constitute metals that still remain in the solid form or in silicate minerals. Metals in the first three fractions have the potential to leach out to the soil provided the soil $\mathrm{pH}$ is conducive enough for them to be in the available form in the soil water.

The current study was carried out at selected agricultural areas in Peninsular Malaysia on different types of soil of different origins. Soils developed on weathered rock were represented by the soils from Cameron Highlands and Cheras in the state of Pahang and Selangor respectively. The soils of mixed nature, developed on hill slopes were represented by soil samples from Kajang and Serdang in the state of Selangor. Samples of paddy soils were collected from Muda in the state of Kedah, Arau in the state of Perlis, Besut in the state of Terengganu and Bumbung Lima in the state of Penang. Alluvial soil from non-paddy cultivated areas was collected from Bangi, Sitiawan, Marang and Tumpat in the state of Selangor, Perak, Terengganu and Kelantan respectively.

Soils samples were collected from 0 to $30 \mathrm{~cm}$ depth at each sampling station. The soil samples were airdried in the laboratory environment followed by grinding with mortar and pestle. $10 \mathrm{~g}$ samples were weighed into kartel bottles, followed by the addition of $50 \mathrm{~mL}$ of $1.0 \mathrm{M} \mathrm{NH} \mathrm{CH}_{3} \mathrm{COO}(\mathrm{pH} \mathrm{7})$. The samples were then shaken for $1-1 \frac{1}{2} \mathrm{~h}$, followed by centrifuging at $3000 \mathrm{rpm}$ for half an hour. This was followed by filtering through $0.45 \mu \mathrm{m}$ pore size membrane filter paper. Then $50 \mathrm{~mL}$ of distilled-dionized water was used for the washing process following the same procedure to free it from the first ELFE reagent. The filtered samples were labelled as Easily Leachable and Ion Exchange fraction (ELFE). The second step in the extraction process was to add $50 \mathrm{~mL}$ of $0.25 \mathrm{M}$ $\mathrm{NH}_{2} \mathrm{OH} . \mathrm{HCl}$ followed by the same process of shaking, 
centrifuging and washing. This second fraction was labelled Acid Reducible fraction (AR). For the third fraction, $15 \mathrm{~mL}$ of $\mathrm{H}_{2} \mathrm{O}_{2}$ was added into the kartel bottles followed by placing them in a water bath for 2$2 \frac{1}{2} \mathrm{~h}$. The samples were cooled off prior to adding 50 $\mathrm{mL}$ of $1.0 \mathrm{M} \mathrm{NH} \mathrm{NH}_{3} \mathrm{COO}$ acidified with $\mathrm{HCl}$ to $\mathrm{pH}$ 3.5. The process was carried out in the same manner as described above. The filtered samples were labelled Organic Oxidation fraction (OO). For the extraction of heavy metals trapped in the mineral silicates or in the basic rock at each particular area, samples were digested using $\mathrm{HNO}_{3}: \mathrm{HClO}_{4}$ (in the ratio 20:10) and heated on a sand bath until the samples became whitish. They were then centrifuged and filtered using the procedure described and distilled-dionized water was added to make it up to $50 \mathrm{~mL}$ of the filtered sample and labelled as Resistant fraction (RR).

The determination of heavy metals in the soil was carried out using the ICP-Plasma. The other research parameters included in the study were soil $\mathrm{pH}$ (Duddridge and Wainright, 1981), organic matter content (Walkley and Black, 1934) and grain size (Badri and Aston, 1983). All the treatments were conducted in triplicate.

\section{RESULTS}

\subsection{Total Mn Concentration in Agricultural Soils}

In this study, the total Mn concentration in weathered soils was significantly higher than that of alluvial and peat deposits (Fig. 1). In the vegetable farming areas of Cameron Highlands and Cheras, the soil Mn concentration was 720.27 and $885 \mathrm{mg} \mathrm{kg}^{-1}$ respectively.

Manganese concentration in the alluvial soils of the study areas ranged from 10.11 to $158.89 \mathrm{mg} \mathrm{kg}^{-1}$ whereas in peat soils of Sepang, the total Mn concentration recorded was $87.97 \mathrm{mg} \mathrm{kg}^{-1}$. Manganese concentration in alluvium deposited at the inland valleys (Bangi, Besut) was higher than that of the alluvium deposited in areas further from the source rocks (Marang, Tumpat, Sitiawan).

\subsection{Manganese Speciation in Agricultural Soils}

Manganese speciation in agricultural soils of Peninsular Malaysia varied widely (Table 1). Generally, different speciation was observed in soils developed on weathered rocks, hill slopes, alluvium (paddy and nonpaddy soils) and peat deposits. In soils developed on weathered rocks, Mn tended to occur in the resistant form. Nearly half of the soil Mn in Cameron Highlands and Cheras were concentrated in the RR fraction, indicating its presence in the resistant form. The Mn concentration in each fraction was in the following decreasing order: RR $>$ OO AR $>\operatorname{ELFE}$ (Fig. 2).

The agricultural soils of Kajang and Serdang constituted soils of mixed nature developed from eroded materials on hill slopes. The soils were acidic ( $\mathrm{pH} 6.57$ and 4.17 respectively), low in organic carbon content ( 1.28 and $0.13 \%$ respectively) and sandy. More than half of the soil $\mathrm{Mn}$ in Kajang and Serdang accumulated in the $\mathrm{OO}$ fraction (Fig. 2). It was followed by the ELFE, RR and AR fractions.

The coastal plain of Peninsular Malaysia constitutes alluvial and peat deposits of the Quaternary era. Generally, the alluvium is comprised of clay, silt, sand and gravel deposited at marine and terrestrial environments, whereas peat deposits are accumulated locally at swampy areas (Bosch, 1988; Tjia and Sharifah Mastura, 2013). Manganese speciation in alluvial deposits varied, depending on the type of agricultural activities, which are identified as the waterlogged paddy cultivation method and the nonpaddy cultivated areas. Paddy cultivation in the state of Kedah and other areas including Arau, Bumbung Lima and Besut is carried out on the alluvial deposits of marine and terrestrial origin, as well as on peat deposits. In these areas, Mn (in paddy soils) has always been highly concentrated in the ELFE fraction, indicating the bioavailable form. With the exception of Bumbung Lima (RR fraction), the Mn concentration in these paddy areas was also high in the AR fraction. The Mn speciation in the paddy soils of Kedah, Arau and Besut was in the following decreasing order: ELFE $>A R>O O>R R$ whereas in Bumbung Lima the order was as follows: ELFE $>$ RR $>A R>O O$ (Fig. 3).

Manganese speciation in the alluvial deposits of nonpaddy cultivated areas is widely varied. In Bangi area, the Mn speciation was in the following decreasing order: AR>OO $>$ RR $>$ ELFE. In Sitiawan, the concentration of Mn was highly associated with the RR fraction, followed by that in the AR, OO, ELFE fractions. In Marang, the Mn speciation was as follows: $\mathrm{AR}>\mathrm{ELFE}>\mathrm{OO}>\mathrm{RR}$, whereas in Tumpat, Mn concentration was higher in the AR fraction, followed by that in the OO, RR and ELFE fractions. In the peat soils of Sepang, more than half $(55.16 \%)$ of the soil Mn was associated with organic carbon. 
J. Habibah et al. / American Journal of Environmental Science 10 (2): 148-156, 2014

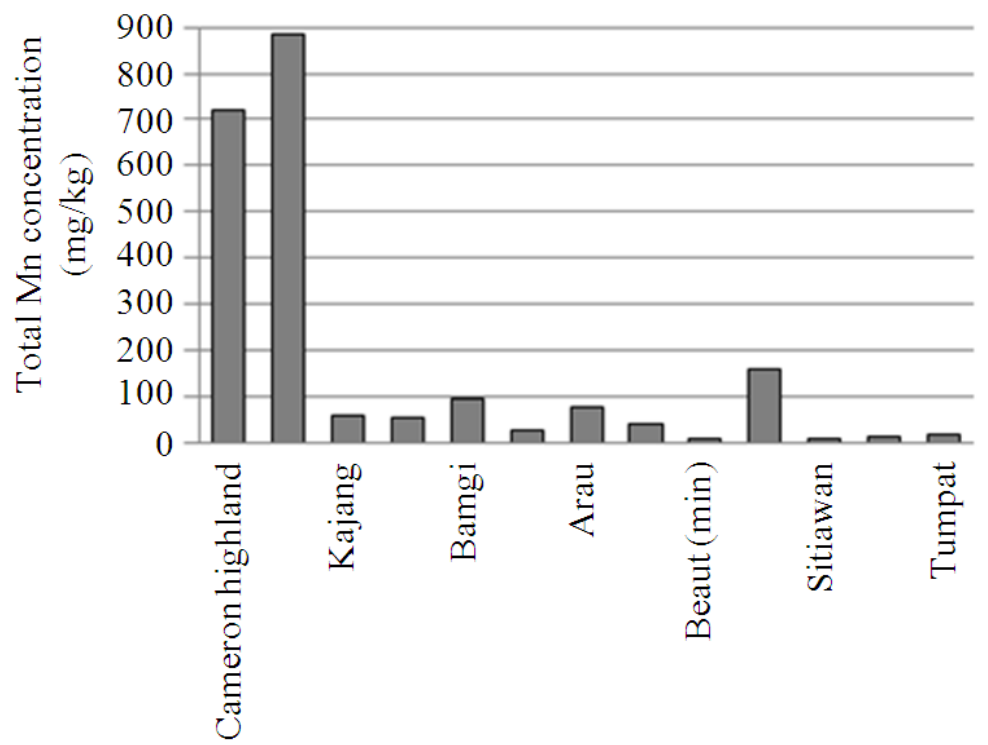

Agricultural area

Fig. 1. Total manganese concentration in agricultural soils

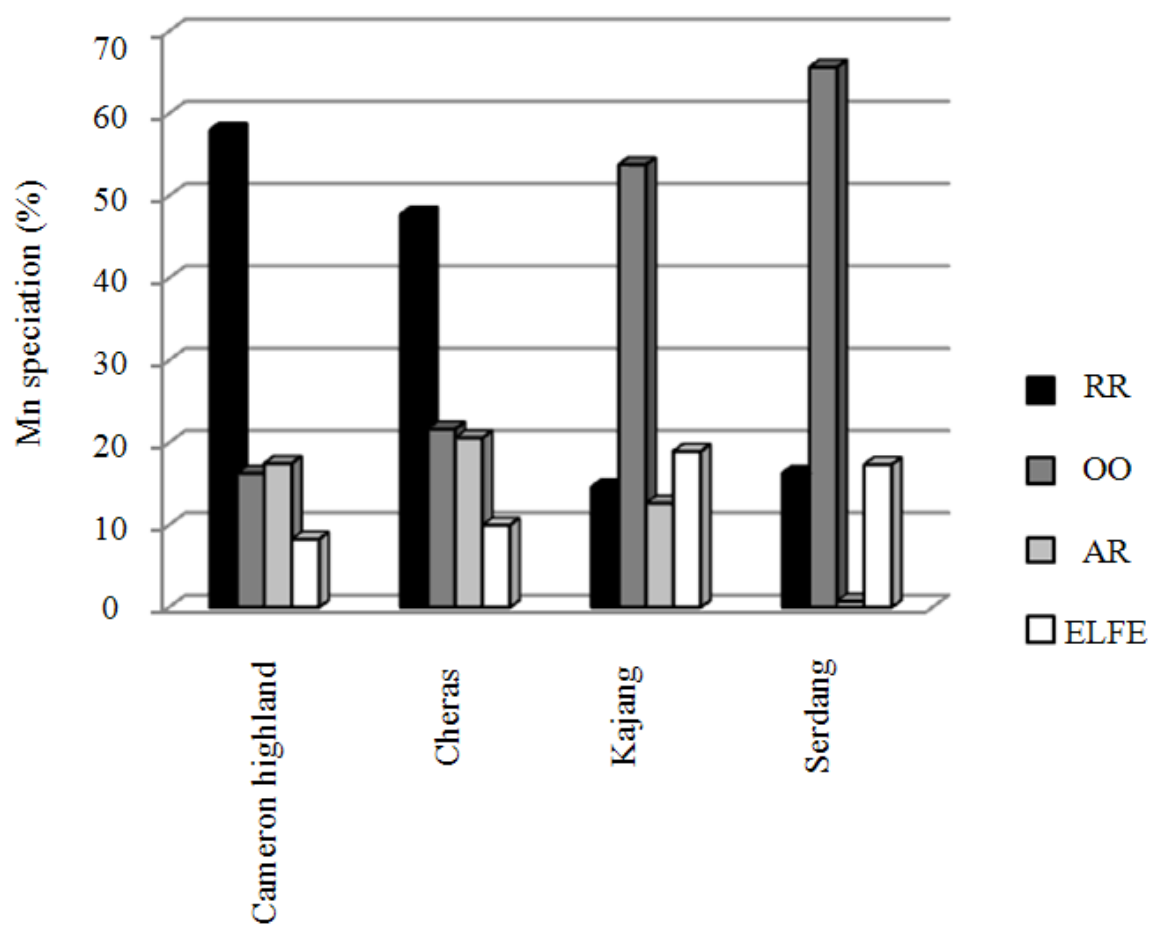

Agricultural areas

Fig. 2. Mn speciation in agricultural soils developed on the weathered rocks and the soils of mixed nature on hill slopes 


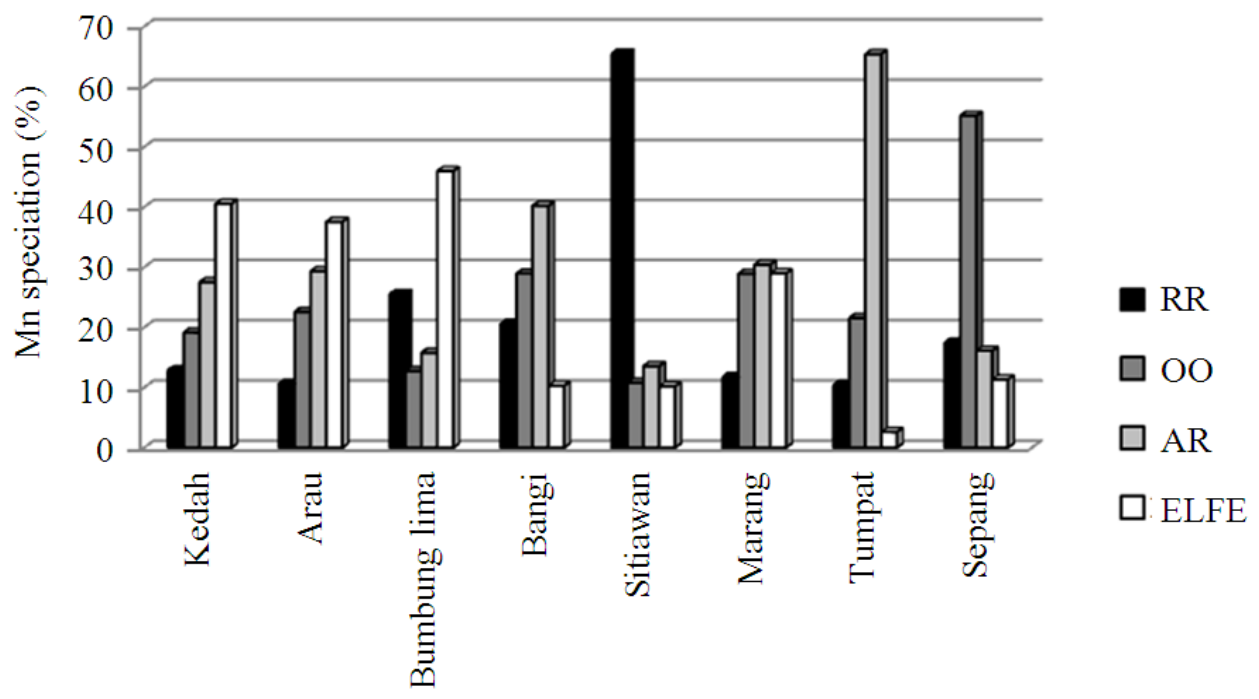

Agricultural area

Fig. 3. Mn speciation in soils developed on alluvial and peat deposits (paddy and non-paddy cultivated areas)

Table 1. Mn speciation, $\mathrm{pH}$, organic carbon content and grain size (less than $63 \mu \mathrm{m}$ ) of agricultural soils in Peninsular Malaysia

\begin{tabular}{|c|c|c|c|c|c|c|c|c|c|}
\hline \multirow[b]{2}{*}{ Agricultural area } & \multicolumn{5}{|c|}{ Mn speciation (mg/kg) } & \multirow[b]{2}{*}{$\mathrm{pH}$} & \multirow{2}{*}{$\begin{array}{l}\text { Organic } \\
\text { carbon } \\
\text { content }(\%)\end{array}$} & \multirow{2}{*}{$\begin{array}{l}\text { Grain size } \\
\text { less than } 63 \\
\mu \mathrm{m}(\%)\end{array}$} & \multirow[b]{2}{*}{ Sources } \\
\hline & RR & $\mathrm{OO}$ & RA & ELFE & Total & & & & \\
\hline Cameron highlands & 417.73 & 117.07 & 125.90 & 59.57 & 720.27 & 6.75 & 2.23 & 42.33 & Khairiah et al. (2006) \\
\hline Cheras & 422.70 & 191.70 & 182.30 & 88.40 & 885.10 & 7.23 & 2.43 & 9.10 & Khairiah et al. (2006) \\
\hline Kajang & 8.52 & 31.36 & 7.38 & 11.04 & 58.30 & 6.57 & 1.28 & 15.72 & Current study \\
\hline Serdang & 8.97 & 36.16 & 0.41 & 9.55 & 55.09 & 4.17 & 0.13 & 31.28 & Current study \\
\hline Kedah & 3.31 & 4.93 & 7.08 & 10.44 & 25.76 & 4.94 & 5.67 & 80.82 & Khairiah et al. (2009c) \\
\hline Arau & 8.08 & 17.17 & 22.31 & 28.58 & 76.14 & 4.63 & 5.53 & 73.15 & Khairiah et al. (2009c) \\
\hline Bumbung Lima & 10.14 & 5.06 & 6.26 & 18.26 & 39.73 & 6.54 & 5.12 & 82.00 & Habibah et al. (2011) \\
\hline Besut & $\begin{array}{l}0.65- \\
8.45\end{array}$ & $\begin{array}{c}0.42- \\
11.19\end{array}$ & $\begin{array}{r}2.09- \\
126.41\end{array}$ & $\begin{array}{l}3.45- \\
14.01\end{array}$ & $\begin{array}{r}8.87- \\
158.89\end{array}$ & $\begin{array}{l}5.45- \\
6.12\end{array}$ & $\begin{array}{l}1.46- \\
9.86\end{array}$ & $\begin{array}{l}67.37- \\
76.82\end{array}$ & Khairiah et al. (2012) \\
\hline Sitiawan & 6.62 & 1.09 & 1.37 & 1.03 & 10.11 & 4.76 & 1.42 & 64.50 & Khairiah et al.(2009a) \\
\hline Bangi & 19.95 & 28.05 & 38.93 & 9.96 & 96.89 & 6.83 & 1.24 & 17.54 & Khairiah et al. (2009b) \\
\hline Marang & 1.54 & 3.79 & 3.99 & 3.80 & 13.12 & 6.03 & 2.56 & 32.40 & Current study \\
\hline Tumpat & 1.72 & 3.55 & 10.77 & 0.43 & 16.47 & 5.78 & 1.78 & 13.67 & Current study \\
\hline Sepang & 15.31 & 48.52 & 14.18 & 9.96 & 87.97 & 4.52 & 26.85 & 58.26 & Khairiah et al. (2009b) \\
\hline
\end{tabular}

\section{DISCUSSION}

In this study, it was found that total $\mathrm{Mn}$ concentration in agricultural soils depended on the soil composition, which reflected their origin. Soils that originated from weathered rocks naturally reflected the constituents of their parent material. According to Uren (2013), the concentration of Mn in soil derived from rocks which contained high proportions of ferromagnesian minerals (1300-2200 $\mathrm{mg} \mathrm{kg}{ }^{-1}$ ) was higher than that of felsic igneous rocks
(500 mg kg-1). The concentration of Mn oxyhydroxide is also high in lateritic soil on serpentine bedrock (Tashakor et al., 2011). Cameron Highlands and Cheras agricultural areas constituted weathered felsic igneous rocks and the total Mn concentration in both areas reflected the natural origin of this metal. The sandy natured soils of Marang, Tumpat and Sitiawan could also have contributed to the lower Mn content. The lower amount of manganese in sandy soil was due to the manganese occurrence as coated Mn oxides on the sediment surface (Kämpf et al., 2000). 
In this study, Mn speciation was widely varied according to the soil composition, which in turn reflected their parent materials. In soils originated from weathered igneous rocks, $\mathrm{Mn}$ was highly concentrated in the Resistant (RR) form. Conversely, its concentration in the available form (ELFE) was almost non-existence.

In igneous rocks, $\mathrm{Mn}^{2+}$ primarily replaced $\mathrm{Fe}^{2+}, \mathrm{Mg}^{2+}$ and ions of similar size in silicates. Upon weathering, the minerals or rocks disintegrated and manganese ions were released into the environment. Mechanical decomposition of granite, accompanied by some leaching of biotite, can be connected locally with the loss of two thirds of the primary manganese content (Wedepohl et al., 1970). The fate of Mn depended substantially upon the leaching of the divalent manganese $\left(\mathrm{Mn}^{2+}\right)$ in solution, mainly as the bicarbonate $\left(\mathrm{Mn}\left(\mathrm{HCO}_{3}\right)_{2}\right)$ and the precipitation of very insoluble hydroxides and oxides of trivalent $\left(\mathrm{Mn}^{3+}\right)$ or quadrivalent manganese $\left(\mathrm{Mn}^{4+}\right)$. The $\mathrm{Mn}^{2+}$ released from minerals was immediately reprecipitated as insoluble $\mathrm{MnO}_{2}$, if conditions permitted. Only a minor proportion was lost in the surface run-off (Kämpf et al., 2000). A study on weathered schist associated with $U$ mineralisation showed strong enrichment of REEs in Mn oxide accumulation zones. The deposition of Mn-phases, appear to have led to the enrichment of $\mathrm{Ce}$ relative to the other REEs. This differential enrichment suggests a redox mediated process involving Mn oxy-hydroxide surfaces (Koppi et al., 1996).

The soil $\mathrm{pH}$ in Cameron Highlands and Cheras was 6.75 and 7.23 respectively. In such conditions, the solubility of Mn will be affected by the redox conditions (Kyuma, 2004). In a humid tropical country like Malaysia, the weathering processes is dominated by oxidation (Shamshuddin and Ishak, 2010), resulting in the formation of $\mathrm{MnO}_{2}$. Similarly, in the present study, the soils that were developed on weathered rocks contained high amounts of resistant $\mathrm{MnO}_{2}$ as indicated by the high level of $\mathrm{Mn}$ in the RR fraction.

In the present study, even though the organic carbon content in agricultural soils of Kajang and Serdang was low, Mn tend to accumulate with the soil organic carbon. According to Adriano (1986), organic soils act as an effective sorbent compared to mineral soils in an acidic environment. This is consistent with the results of a study on paddy soil which showed that the EDTA-extractable content of $\mathrm{Cr}, \mathrm{Cu}, \mathrm{Fe}, \mathrm{Mn}, \mathrm{Pb}$ and $\mathrm{Zn}$ were negatively correlated with the soil $\mathrm{pH}$, but positively correlated with the organic matter content (Zeng et al., 2011).
Manganese speciation in paddy soils of the study areas was observed to have been influenced by redox conditions. The seasonal wetting and drying cycles throughout the paddy cultivation controlled the dissolution and precipitation of Mn-oxyhydroxides. Manganese was mobilized by reduction and then precipitated upon oxidation into various forms, such as pore infillings, mottles and concretions (Adriano, 1986; Kyuma, 2004; Mancheau et al., 2005). The presence of both iron and $\mathrm{Mn}$ mottles and concretions were reported in paddy soils of the Kemubu Plain (Paramananthan, 1989). In flooded soils, Mn(IV) was reduced to $\mathrm{Mn}(\mathrm{II})$ thus increasing the water-soluble $\mathrm{Mn}^{2+}$ ions in paddy soils. Upon drying, Mn was oxidized into the resistant Fe-Mn mottles and occluded as oxides and hydroxides. Mancheau et al. (2005) reported that ferromanganiferous (FeMnMot) mottles in clayey paddy soils were enriched with both Fe and Mn, whereby, Mn occurred as resistant lepidocrocite and birnessite. Manganese in the background mass occurred as Mn-oxyhydroxides. Upon flooding, the reducing condition recurred, rendering the dissolution of the Mn-oxyhydroxides and $\mathrm{Mn}^{2+}$ was liberated. This condition explains the high percentage of $\mathrm{Mn}$ in the bioavailable form (ELFE), followed next in the Acid Reducible (AR) and unavailable Resistant (RR) forms.The changes of Mn oxidation state was also observed at the oxic-anoxic interface of the continental slope sediments (Anschutz et al., 2005).

Apart from the redox condition, the high percentage of bioavailable $\mathrm{Mn}$ in paddy soils might be attributed to the application of fertilizers containing Mn during paddy cultivation. Anthropogenic heavy metals tend to occur in the bioavailable form. However, Mn toxicity has not been observed in the paddy soils of Peninsular Malaysia because the amount of bioavailable $\mathrm{Mn}$ is well below the threshold level. The threshold level for Mn toxicity is $>300 \mathrm{mg} \mathrm{kg}^{-1}$ of readily reducible Mn (Kyuma, 2004). Furthermore, this metal is an essential micronutrient.

Manganese speciation in the alluvial deposits of nonpaddy cultivated areas varied widely and is less understood. The inconsistent Mn speciation in soils could be related to the grain size sediments and its present environmental condition. According to Schulte and Kelling (1999), the acidic sandy soils are likely to contain high manganese levels. Excess manganese levels tend to occur in acidic soils $(\mathrm{pH})$ especially when these soils are low in organic matter and temporarily waterlogged. Generally, the non-paddy cultivated areas of Peninsular Malaysia were highly exposed to oxidizing conditions. The soils were occasionally submerged by shallow water table during the rainy season. The seasonal 
moisture change and the presence of interfering organic and inorganic components in the soil solution could possibly be related to the occurrence of fine grain size and poor crystallinity of $\mathrm{Mn}$ oxides in soils (Kämpf et al., 2000). In the current study, Mn oxides could reflect the occurrence of $\mathrm{Mn}$ in the RR and AR fractions. Apart from that, $\mathrm{Mn}$ speciation in the agricultural soils of alluvial deposits might be attributed to the soil composition due to the distance from the source materials and grain size distribution. More detailed studies are needed to understand Mn speciation in soils with respect to both parameters.

In peat soil, Mn tends to be associate with soil organic matter. According to Adriano (1986), high accumulation of $\mathrm{Mn}$ in organic matter was attributed to organic matter complexation, particularly, humic acid. Organic matter is widely known for its ability to absorb heavy metals and is less $\mathrm{pH}$-dependent than sorption by mineral soils. Hence, the high Mn concentration in the OO fraction was not surprising since soils in the Sepang area were rich in organic carbon content $(26.85 \%)$. The factors that determine the available fraction for some elements are their physicochemical and biological properties, such as soil $\mathrm{pH}$, the prevailing redox conditions, extent of organic matter degradation, grain size distribution, water content and microbial activity that could change with time (Tagami and Uchida, 1998).

\section{CONCLUSION}

The total Mn concentration was significantly higher in soils developed on weathered rocks compared to those from the eroded materials, alluvium and peat deposits. Most of the soil Mn in weathered rocks was concentrated as the resistant manganese oxides at the topsoils. In the soils of mixed nature, formed from eroded materials on the hill slopes, Mn tended to be associated with the organic carbon. Manganese speciation in the waterlogged paddy soils was influenced by the redox conditions caused by alternate seasonal wetting and drying conditions. In paddy soils, Mn concentration is highest in the bioavailable form, followed by the AR and RR forms. In the non-paddy cultivated alluvial soils, Mn speciation was more varied and less predictable. Manganese in peat soils was highly associated with the organic matter, as indicated by the high $\mathrm{Mn}$ concentration in the $\mathrm{OO}$ fraction.

\section{ACKNOWLEDGEMENT}

Thanks and appreciations are extended to UKM for providing financial support for a series of studies on heavy metal speciation in Malaysia.

\section{REFERENCES}

Adriano, D.C., 1986. Trace Elements in the Terrestrial Environment. 1st Edn., Springer-Verlag, New York, ISBN-10: 3540961585, pp: 533.

Anschutz, P., K. Dedieu, F. Desmazes and G. Challiou, 2005. Speciation, oxidation state and reactivity of particulate manganese in marine sediments. Chemical Geol., 218: 265-279. DOI: 10.1016/j.chemgeo.2005.01.008

Badri, M.A. and S.R. Aston, 1983. Observation on heavy metal geochemical associations in polluted and non polluted estuarine sediments. Environ. Poll. (Series B), 6: 181-193. DOI: 10.1016/0143148X(83)90033-2

Bosch, J.H.A., 1988. The Quaternary Deposits in the Coastal Plains of Peninsular Malaysia. 1st Edn., Geological Survey of Malaysia, Quaternary Geology Section, Kuala Lumpur, pp: 174.

Clark, R.B.S., 1993. The American Phytopathological Society. In: Nutrient Deficiencies and Toxicities in Crop Plants, Bennett, W.F. (Ed.), APS Press, St. Paul, MN, ISBN-10: 0890541515, pp: 21-26.

Decree, S., G. Ruffet, T. De Putter, J.M. Baele and P. Recourt et al., 2010. Mn oxides as efficient traps for metal pollutants in a polyphase lowtemperature Pliocene environment: A case study in the Tamra iron mine, Nefza mining district, Tunisia. J. Afr. Earth Sci., 57: 249-261. DOI: 10.1016/j.jafrearsci.2009.08.005

Duddridge, J.E. and M. Wainright, 1981. Heavy metal in river sediments-calculation of metal adsorption maxima using Langmuir and Freundlich isotherms. Environ. Poll., 2: 387-397. DOI: 10.1016/0143-148X(81)90061-6

Gupta, U.C., W. Kening and L. Siyuan, 2008. Micronutrients in soils, crops and livestock. Earth Sci. Front., 15: 110-125. DOI: 10.1016/S18725791(09)60003-8

Habibah, J., P.T. Lee, J. Khairiah, R. Ahmad-Mahir and B.A. Fouzi et al., 2011. Speciation of heavy metals in paddy soils from selected areas in Kedah and Penang, Malaysia. Afr. J. Biotechnol., 10: 13505-13513.

Iskandar, I.K. and M.B. Kirkham, 2001. Trace Elements in Soil: Bioavailability, Flux and Transfer. 1st Edn., CRC Press, ISBN-10: 156670507X, pp: 304.

Kabata-Pendias, A. and H. Pendias, 1984. Trace Elements in Soils And Plants. 1st Edn., CRC Press, Boca Raton, Fla, ISBN-10: 0849366399, pp: 315. 
Kämpf, N., A.C. Scheinost and P.G. Schulze, 2000. Oxide Minerals. In: Handbook of Soil Science. Sumner, M.E. (Ed.), CRC Press, Boca Raton, FL, ISBN-10: 0849331366, pp: F125-F168.

Khairiah, J., Y. Ding-Woei, J. Habibah, R. AhmadMahir and A. Aminah et al., 2009a. Concentration of heavy metals in guava plant parts and soil in the sungai wangi plantation, Perak, Malaysia. Int. J. Agric. Res., 4: 310-316. DOI: 10.3923/ijar.2009.310.316

Khairiah, J., J. Habibah, R.A. Mahir, R. Maimon and A. Aminah et al., 2009b. Studies on heavy metal deposits in soils from selected agricultural areas of Malaysia. Adv. Environ. Biol., 3: 329-336.

Khairiah, J., J. Habibah, I. Anizan, A. Maimon and A. Aminah et al., 2009c. Content of heavy metals in soil collected from selected paddy cultivation areas in kedah and perlis, Malaysia. J. Applied Sci. Res., 5: 2179-2188.

Khairiah, J., K.H. Lim, R. Ahmad-Mahir and B.S. Ismail, 2006. Heavy metals from agricultural soils from Cameron Highlands, Pahang and Cheras, Kuala Lumpur, Malaysia. Bull. Environ. Contaminat. Toxicol., 77: 608-615. DOI: 10.1007/s00128-006-1106-8

Khairiah, J., M.S.M. Tharmendren, J. Habibah, H. Zulkefly and W.I. Wan Kamal et al., 2012. Heavy metal content in paddy soils of Ketara, Besut, Terengganu, Malaysia. World Applied Sci. J., 19: $183-191$.

DOI: 10.5829/idosi.wasj.2012.19.02.3687

Koppi, A.J., R. Edis, D.J. Field, R.'Harold and H.R. Geering, 1996. Rare earth element trends and cerium-uranium-manganese associations in weathered rock from Koongarra, Northern Territory, Australia. Geochim. Cosmochim. Acta, 60: 1695-1707. DOI: 10.1016/00167037(96)00047-6

Kyuma, K., 2004. Paddy Soil Science. 1st Edn., Kyoto University Press, Rosanna, Vic, ISBN-10: 1920901000, pp: 280.

Mancheau, A., C. Tommaseo, S. Rihs, N. Geoffroy and D. Chateigner et al., 2005. Natural speciation of $\mathrm{Mn}, \mathrm{Ni}$ and $\mathrm{Zn}$ at the micrometer scale in a clayey paddy soil using X-ray fluorescence, absorption and diffraction. Geochem. Cosmochim. Acta, 69: 4007-4034. DOI: 10.1016/j.gca.2005.03.018
Marchand, C., E. Lallier-Verges, F. Baltzer, P. Alberic and D. Cossa et al., 2006. Heavy metals distribution in mangrove sediments along the mobile coastline of French Guiana. Marine Chem., 98: 1-17. DOI: 10.1016/j.marchem.2005.06.001

Moraghan, J.T., 1979. Manganese toxicity in flax growing on certain calcareous soils low in available iron. Soil Sci. Soc. Am., 43: 1177-1180. DOI: 10.2136/sssaj1979.03615995004300060024x

Paramananthan, S., 1989. A comparative study of the mineralogy of rice soils of the Kedah and Kelantan Coastal Plains of Peninsular Malaysia. Geol. Soc. Malaysia Bull., 23: 41-57.

Quemerais, B., D. Cossa, B. Rondeau, T.T. Pham and B. Fortin, 1998. Mercury distribution in relation to iron and manganese in the water of the St. Laurent River. Sci. Total Environ., 213: 193-201. DOI: 10.1016/S0048-9697(98)00092-8

Rajoo, K.S., A. Abdu, H. Abdul-Hamid, D.S. Karam and S. Jusop et al., 2013. Assessment of heavy metals uptake and translocation by Aquilaria malaccensis planted in soils containing sewage sludge. Am. J. Applied Sci., 10: 952-964. DOI: 10.3844/ajassp.2013.952.964

Schulte, E.E. and K.A. Kelling, 1999. A2526 Soil and applied manganese. Understanding plant nutrients. Cooperative Extension Publications, University of Wisconsin-Extension.

Shamshuddin, J. and C.F. Ishak, 2010. Weathered Tropical Soils: The Ultisols and Oxisols. 1st Edn., Universiti Putra Malaysia Press, Serdang, ISBN10: 9673441464, pp: 147.

Tagami, K. and S. Uchida, 1998. Aging effect on bioavailability of $\mathrm{Mn}, \mathrm{Co}, \mathrm{Zn}$ and Tc in Japanese agricultural soils under waterlogged conditions. Geoderma, 84: 3-13. DOI: 10.1016/S00167061(97)00117-1

Tan, W.F., F. Liu, X. Feng, Q. Huang and X. Li, 2005. Adsorption and redox reactions of heavy metals on Fe-Mn nodules from Chinese soils. J. Colloid Interface Sci., 284: 600-605. DOI: 10.1016/j.jcis.2004.10.049

Tashakor, M., W.Z.W. Yaacob and H. Mohamad, 2011. Speciation and availability of $\mathrm{Cr}, \mathrm{Ni}$ and $\mathrm{Co}$ in serpentine soils of Ranau, Sabah. Am. J. Geosci., 2: 4-9. DOI: 10.3844/ajgsp.2011.4.9 
Tjia, H.D. and S.A. Sharifah Mastura, 2013. Sea Level Changes in Peninsular Malaysia: A Geological Record. 1st Edn., Penerbit Universiti Kebangsaan Malaysia, Malaysia, ISBN-10: 9674121404, pp: 150.

Uren, N.C., 2013. Cobalt and Manganese. In: Heavy Metals in Soils: Trace Metals and Metalloids in Soils and their Bioavailability, Alloway, B.J. (Ed.), Springer, Dordrecht, ISBN-10: 9400744706, pp: 335-366.

Walkley, A. and I.A. Black, 1934. An examination of the degtjareff method for determining soil organic matter and a proposed modification of the chromic acid titration method. Soil Sci., 37: 29-38.
Wedepohl, K.H., C.W. Correns, D.M. Shaw, K.K. Turekian and J. Zemann, 1970. Handbook of Geochemistry. 2 Edn., Springer-Verlag, Berlin.

Wiese, M.V., 1993. Wheat and Other Small Grains. In: Nutrient Deficiencies and Toxicities in Crop Plants, Bennett, W.F. (Ed.), APS Press, St. Paul, ISBN-10: 0890541515, pp: 202.

Zeng, F., S. Ali, H. Zhang, Y. Ouyang and B. Qiu et al., 2011. The influence of $\mathrm{pH}$ and organic matter content in paddy soil on heavy metal availability and their uptake by rice plants. Environ. Poll., 159: 84-91. DOI: 10.1016/j.envpol.2010.09.019 